\title{
High-Flow Nasal Cannulae for Respiratory Support of Preterm Infants: A Review of the Evidence
}

\author{
Brett J. Manley ${ }^{\mathrm{a}-\mathrm{c}}$ Simone K. Dold ${ }^{\mathrm{d}}$ Peter G. Davis ${ }^{\mathrm{a}-\mathrm{c}}$ Charles C. Roehr ${ }^{\mathrm{d}}$ \\ ${ }^{a}$ Newborn Research Centre, The Royal Women's Hospital, ${ }^{b}$ Department of Obstetrics and Gynaecology, \\ The University of Melbourne, and ${ }^{C}$ Critical Care and Neurosciences Theme, Murdoch Childrens Research Institute, \\ Melbourne, Vic., Australia; ${ }^{d}$ Department of Neonatology, Charité University Medical Center, Berlin, Germany
}

\section{Key Words}

Infant, premature $\cdot$ Continuous positive airway pressure $\cdot$

High-flow nasal cannulae $\cdot$ Intensive care, neonatal

\section{Abstract}

Background: High-flow nasal cannulae (HFNC) are gaining in popularity as a form of non-invasive respiratory support for preterm infants in neonatal intensive care units around the world. They are proposed as an alternative to nasal continuous positive airway pressure (NCPAP) in a variety of clinical situations, including post-extubation support, primary therapy from birth and 'weaning' from NCPAP. Objectives: To present and discuss the available evidence for the use of HFNC in the preterm population. Methods: An internetbased literature search for relevant, original research articles (both randomised studies and not) on the use of HFNC in preterm infants was undertaken. Results: A total of 19 studies were included in the review. Distending pressure generated by HFNC in preterm infants increases with increasing flow rate and decreasing infant size and varies according to the amount of leak around the prongs. HFNC may be as effective as NCPAP at improving respiratory parameters such

\section{KARGER}

Fax +4161306 1234

E-Mail karger@karger.ch

www.karger.com (c) 2012 S. Karger AG, Basel

1661-7800/12/1024-0300\$38.00/0

Accessible online at:

www.karger.com/neo as tidal volume and work of breathing in preterm infants, but probably only at flow rates $>2$ litres $/ \mathrm{min}$. The efficacy and safety of HFNC in preterm infants remain to be determined. Conclusions: There is growing evidence of the feasibility of HFNC as an alternative to other forms of non-invasive ventilation in preterm infants. However, there remains uncertainty about the efficacy and safety of HFNC in this population. Until the results of larger randomised trials are known, widespread use of HFNC to treat preterm infants cannot be recommended.

Copyright $\odot 2012$ S. Karger AG, Basel

\section{Introduction}

Binasal cannulae that deliver high gas flows (highflow nasal cannulae, HFNC) are becoming a popular form of respiratory support for preterm infants. Definitions of 'high' flow vary; a flow rate $>1$ litre/min was used in the recent Cochrane review [1]. HFNC are used to treat older children, particularly those with viral respiratory tract infections, and there is increasing evidence of their efficacy in this population [2-4]. The clinical application

Dr. Brett J. Manley, MBBS, FRACP

Newborn Research Centre, Level 7, The Royal Women's Hospital 20 Flemington Road

Parkville, VIC 3052 (Australia)

Tel. +61 38345 3766, E-Mail brett.manley@thewomens.org.au 
of HFNC has been described for neonatal intensive care units in the USA [5-7], United Kingdom [8] and Australia and New Zealand [9]. In preterm infants, HFNC are used as a primary support for respiratory distress syndrome (RDS), for treating apnoea of prematurity (AOP), to support preterm infants after extubation and to wean from nasal continuous positive airway pressure (NCPAP). HFNC are also embraced by smaller, nontertiary nurseries because they are easier to apply than NCPAP [10] and because they allow greater access to the baby's face, which may improve feeding and bonding. The commercially available HFNC systems are open systems with leaks at the nose and mouth. These systems effectively humidify delivered gas $[11,12]$ and provide a means to blend oxygen with air. A range of nasal prong sizes is available.

The Cochrane review of HFNC use in preterm infants [1] included only four small randomised studies comparing HFNC with other forms of respiratory support in a total of 177 preterm infants; three of these studies are published [13-15] and one is unpublished [Nair and Karna, unpubl. data]. Heterogeneity of interventions and outcomes made meta-analysis inappropriate. The authors concluded that there is insufficient evidence to establish the safety or effectiveness of HFNC as a form of respiratory support in preterm infants.

We aim to provide a comprehensive review of the available evidence for the use of HFNC in preterm infants, including and beyond data derived from randomised trials.

\section{Search Strategy}

An internet-based literature search for relevant, original research articles on the use of HFNC in preterm infants was performed (last completed 29 March 2012). We searched PubMed, Medline, CINAHL, Embase and the Cochrane Library using the search terms [high flow OR high-flow] AND nasal cannula*, with no language restriction. This search produced a total of 138 individual articles. We excluded studies not relevant to the preterm population, letters to the editor, review articles or commentaries and articles only available as abstracts. Of the remaining 15 studies, 12 were clinical trials, 1 was an animal study (Frizzola et al. [16]) and 2 were bench-top studies (Hasan and Habib [17] and Volsko et al. [18]). In addition, we included data from the unpublished clinical trial by Nair and Karna that was presented in the Cochrane review. A further three clinical studies (Locke et al. [19], Boumecid et al. [20] and Wilkinson et al. [21]) were found by examining the reference lists of the retrieved articles. Thus, a total of 19 studies are included in this review; 16 of these are clinical studies that are detailed in the Appendix and have been assigned a level of evidence [22].

\section{How Much Distending Pressure Is Generated by HFNC in Preterm Infants?}

Some clinicians are concerned by the generation of unpredictable pulmonary distending pressures when HFNC is applied to newborn infants. Finer [23] and Finer and Mannino [24] noted that with ventilator-generated or bubble NCPAP, the delivered pressure will not exceed the set pressure, but there is no such reassurance with HFNC. Data on HFNC pressure generation come from small, observational, crossover, animal and in vitro studies, which have mainly used oesophageal pressure monitoring to estimate intrapulmonary pressures.

Locke et al. [19] raised concerns about pulmonary over-distension when they measured a mean oesophageal pressure of $9.8 \mathrm{~cm} \mathrm{H}_{2} \mathrm{O}$ using flow rates of 2 litres/min in 13 preterm infants. According to more recent studies, pressures generated by HFNC were similar to or less than those commonly set with NCPAP $[18,21,25,26]$. HFNC pressures increase with increasing flow rates [16-18, 2527] and also with decreasing infant weight [21]. Sreenan et al. [28] studied 40 preterm infants on HFNC and determined the flow rate required to generate an end-expiratory oesophageal pressure equal to that measured during NCPAP at $6 \mathrm{~cm} \mathrm{H} \mathrm{H}_{2} \mathrm{O}$. Wilkinson et al. [21] measured pharyngeal pressures in 18 premature infants receiving HFNC at 2-8 litres/min with the Fisher \& Paykel system (Fisher \& Paykel Healthcare, Auckland, New Zealand), however without the pressure-limiting valve attached that has lately been included with this circuit, and also produced a formula to predict pressure. However, Sreenan et al. [28] predict that 1.6 litres/min in a $1-\mathrm{kg}$ infant will produce a distending pressure comparable to $\mathrm{NCPAP}$ at $6 \mathrm{~cm} \mathrm{H}_{2} \mathrm{O}$, whereas Wilkinson et al. [21] predict that 2 litres/min will produce a pressure of only 2.8 $\mathrm{cm} \mathrm{H}_{2} \mathrm{O}$ in a baby of the same size.

These contrasting results may be due to a number of factors; the published studies have small sample sizes, use different modes and sites of pressure measurement (oral, pharyngeal, tracheal or oesophageal), study infants with heterogeneous gestational ages and weights and study a variety of flow rates and nasal prong sizes. Hence, results 
from these studies should be interpreted with caution. It must be recognized that pressures will vary considerably depending on leak at the mouth (i.e. mouth open vs. closed) $[16,17,21,26,29]$ and presumably also in the presence of nasal obstruction and that these changes in delivered pressure cannot be continuously controlled for by clinicians.

\section{HFNC and Respiratory Mechanics}

Although flow rates of only $0.5-2$ litres/min were studied, Locke et al. [19] were able to demonstrate both the generation of distending pressure with HFNC and a reduction in thoraco-abdominal asynchrony with larger prongs and increased flow. Woodhead et al. [15] performed a small randomized crossover trial of the heated and humidified Vapotherm system (Vapotherm Inc., Stevensville, Md., USA) versus 'standard' unhumidified HFNC; infants in the Vapotherm group had lower respiratory effort scores, which were based on the respiratory rate and chest retractions of the infant, demonstrating the need for proper heating and humidification of delivered gases.

Boumecid et al. [20] studied 19 preterm infants, comparing variable-flow NCPAP at $5 \mathrm{~cm} \mathrm{H}_{2} \mathrm{O}$ to conventional NCPAP at $5 \mathrm{~cm} \mathrm{H}_{2} \mathrm{O}$ and $\mathrm{HFNC}$ at 2 litres/min, applied in a random order. Outcomes included tidal volume $\left(\mathrm{V}_{\mathrm{t}}\right)$, thoraco-abdominal synchrony, respiratory rate and inspiratory times (obtained from respiratory inductive plethysmography). The variable-flow NCPAP increased $\mathrm{V}_{\mathrm{t}}$ and improved thoraco-abdominal synchrony compared to the other modalities, but there was no difference between conventional NCPAP and HFNC.

Saslow et al. [30] compared the $V_{t}$ in premature neonates supported with either HFNC or NCPAP. Eighteen preterm neonates with a birth weight $<2 \mathrm{~kg}$ received either Vapotherm or NCPAP (Infant Bird ventilator, VIASYS Healthcare Inc., Conshohocken, Pa., USA) in a random order and then crossed over to the other treatment. $\mathrm{V}_{\mathrm{t}}$ was measured using respiratory inductive plethysmography at HFNC flow rates of 3-5 litres/min and NCPAP at $6 \mathrm{~cm} \mathrm{H}_{2} \mathrm{O}$. No differences were found between the two treatments at any setting, leading the authors to conclude that HFNC provided comparable respiratory support to NCPAP in this population.

Lampland et al. [27] compared NCPAP at $6 \mathrm{~cm} \mathrm{H}_{2} \mathrm{O}$ with HFNC at 1-6 litres/min in a group of 15 preterm infants with RDS. Measured parameters included heart rate, respiratory rate, fraction of inspired oxygen, arterial oxygen saturation and an 'RDS score'. The only significant finding was the development of tachypnoea with HFNC at flow rates of $1-2$ litres/min $(p<0.02)$. Three patients also developed apnoea and increased oxygen needs when weaned to 1 litre/min.

Frizzola et al. [16] studied gas exchange with HFNC therapy in an animal study. Thirteen neonatal piglets (weight 2-6 kg) with induced lung injury were treated with HFNC at 2-8 litres/min in both high- and low-leak settings. The impact of increasing flow on $\mathrm{CO}_{2}$ removal and oxygenation was independent of the tracheal pressures generated. Both ventilation and oxygenation improved in a flow-dependent manner, independent of leak, and oxygenation was particularly improved in the presence of higher leak. This is interesting, as it indicates improved efficacy with higher leak (and less pressure).

In summary, humidified HFNC systems may have comparable effectiveness to conventional NCPAP in improving important clinical parameters in preterm infants, but probably only at flow rates above 2 litres/min. Dead-space washout from HFNC may be an important additional mechanism of action to distending pressure generation, although this has not been extensively studied.

\section{Clinical Uses of HFNC in Preterm Infants}

\section{HFNC to Prevent Extubation Failure}

HFNC has been proposed as an alternative to NCPAP in neonatal intensive care units for preventing extubation failure. This is despite there being little published evidence to support the effectiveness of HFNC, while a large body of evidence has demonstrated the efficacy of NCPAP in this role [31]. Campbell et al. [13] performed the only randomised controlled trial (RCT), comparing HFNC (which was non-heated, but humidified) to Infant Flow NCPAP (VIASYS Healthcare) as post-extubation support in 40 infants with birth weight $<1,250 \mathrm{~g}$. Significantly more infants in the HFNC group required re-intubation within 7 days than in the NCPAP group (12/20 vs. $3 / 20, p=0.003)$. Infants receiving HFNC required higher oxygen concentrations and experienced more episodes of apnoea and bradycardia. Flow rates were calculated from the formula of Sreenan et al. [28] and ranged from 1.4 to 1.7 litres $/ \mathrm{min}$. These flow rates are much lower than those in current clinical use $[9,10]$ and may explain the poor performance of HFNC in this study. 
Miller and Dowd [14] compared the ability of Vapotherm and Fisher \& Paykel HFNC to prevent re-intubation in premature infants in a prospective RCT funded by the two manufacturers. They found a failure rate of $18 \%$ in the Fisher \& Paykel group and 9\% in the Vapotherm group, but the study was a pilot and not powered to find statistical differences. In the randomized trial of Woodhead et al. [15], no preterm infants receiving Vapotherm failed, but 7 failed standard HFNC. The retrospective, observational study of Holleman-Duray et al. [7] comparing HFNC to NCPAP found no difference in rates of extubation failure, and a retrospective review by Shoemaker et al. [6] found that more infants were intubated for failing NCPAP compared to HFNC (40 vs. $18 \%$; $p=0.03$ ) following the introduction of HFNC. Larger, prospective RCTs of HFNC as post-extubation support are currently under way.

\section{HFNC as Primary Therapy for RDS or AOP}

A few small, non-randomised studies have included infants being treated with HFNC for early or stable RDS or for AOP. The only RCT data are from the unpublished study by Nair and Karna, which was included in the recent Cochrane review. There are no published RCTs that examine the use of early HFNC compared to NCPAP or supplemental oxygen alone.

Saslow et al. [30] conducted a crossover study of preterm neonates who were medically stable on HFNC or NCPAP for treatment of mild RDS, bronchopulmonary dysplasia (BPD) or AOP and showed no difference in $\mathrm{V}_{t}$ on either device. The study of Lampland et al. [27] compared NCPAP at $6 \mathrm{~cm} \mathrm{H}_{2} \mathrm{O}$ to HFNC at 1-6 litres/min in a group of 15 preterm infants with stable RDS and showed only the development of tachypnoea at HFNC $\leq 2$ litres/ min. Sreenan et al. [28] also compared HFNC to NCPAP for $\mathrm{AOP}$ and showed no difference in apnoea severity. The retrospective review of Shoemaker et al. [6] found that ventilator days per patient were decreased (mean 19.4 vs. 9.9 days; $p=0.03$ ) following the introduction of HFNC as early respiratory support.

In Nair and Karna's RCT [unpubl. data], 67 preterm infants who required NCPAP in the first $6 \mathrm{~h}$ of life for RDS were randomised to continue NCPAP at 5-6 cm $\mathrm{H}_{2} \mathrm{O}(\mathrm{n}=34)$ or receive Vapotherm at 5-6 litres/min ( $\mathrm{n}=$ 33). The trial ceased early due to the recall of Vapotherm circuits by the manufacturer (see below). Four infants in each group (approx. 12\%) met pre-determined failure criteria and were intubated. Secondary outcomes, including duration of hospitalisation and the combined outcome of death or BPD, did not differ between the groups.

High-Flow Nasal Cannulae for Preterm Infants
In summary, the use of HFNC as a primary therapy from birth requires further research. If HFNC is shown to be safe and efficacious, it may be a potentially easy-touse alternative to NCPAP. Future trials should compare HFNC to NCPAP in this role, as well as to treatment with supplemental oxygen alone.

\section{HFNC to Wean from NCPAP}

Weaning or 'stepping down' from NCPAP to HFNC treatment is common. Presumably this practice stems from the belief that HFNC is a mild form of NCPAP, and also that convalescing preterm infants with evolving $\mathrm{BPD}$ will benefit from the smaller nasal prongs and less bulky device. We found only two single-centre studies of this use of HFNC.

Abdel-Hady et al. [32] randomised 60 preterm infants ( $\geq 28$ weeks' gestation) who were stable on NCPAP at $5 \mathrm{~cm} \mathrm{H}_{2} \mathrm{O}$ with fraction of inspired oxygen $<0.30$ for at least $24 \mathrm{~h}$ into two groups. The NCPAP group was kept on NCPAP until they required no supplemental oxygen for $24 \mathrm{~h}$ and then placed in air. The HFNC group was changed to humidified HFNC at 2 litres/min. This flow rate was maintained until no supplemental oxygen was required, then decreased by 0.5 litres/min every $6 \mathrm{~h}$ to 0.5 litres/min. The HFNC group had a clinically important increase in days on oxygen (median 14 vs. 5 days; $\mathrm{p}<$ 0.001 ) and duration of respiratory support (18 vs. 10.5 days; $\mathrm{p}=0.03$ ).

Iranpour et al. [33] randomised preterm infants (3035 weeks' gestation) $24 \mathrm{~h}$ after early surfactant treatment and immediate extubation to NCPAP to either continuing NCPAP at $6-8 \mathrm{~cm} \mathrm{H}_{2} \mathrm{O}$ or changing to Fisher \& Paykel HFNC. Flow rates used in the HFNC group were determined from the formula of Sreenan et al. [28]. There were no differences between the groups with regard to shortterm morbidities, duration of hospitalisation or duration of oxygen treatment.

\section{How Safe Is HFNC for Preterm Infants?}

The most widely publicised complication arising from HFNC use in preterm infants was the Ralstonia contamination of the Vapotherm system that forced a temporary recall of these units in 2005 [34]. The Vapotherm system has since been subject to more stringent infection control measures and is back in widespread use. There has also been a case report [35] of a preterm infant who was receiving humidified HFNC at 2 litres/min (device not reported) and concomitantly was found to have subcuta- 
neous scalp emphysema and pneumo-orbitus, which resolved after discontinuation of the HFNC. The authors noted that these complications may have been a result of nasopharyngeal trauma rather than the mode of support.

Few studies have reported other adverse outcomes of importance to neonatal clinicians. In the RCT of Campbell et al. [13], no differences were noted in the incidence of necrotizing enterocolitis, intraventricular haemorrhage, $\mathrm{BPD}$, sepsis or retinopathy of prematurity between the NCPAP and HFNC groups. There were no pneumothoraces in either group. Holleman-Duray et al. [7] found no differences in rates of pulmonary or extra-pulmonary side effects, death, oxygen use or length of admission, but infants in the HFNC era spent fewer days on the ventilator (mean 11.4 vs. 18.5 days; $p=0.028$ ). Iranpour et al. [33] found no differences in rates of death, BPD, pneumothoraces, other short-term morbidities or duration of hospitalisation or oxygen therapy. Shoemaker et al. [6] and Nair and Karna [unpubl. data] also found no difference in rates of death or BPD.

HFNC are thought to be more comfortable for preterm infants and to cause less nasal septal trauma than NCPAP. Three studies have included nasal trauma as an outcome. In the study by Woodhead et al. [15] of humidifying HFNC, the noses of infants were examined by a blinded investigator $24 \mathrm{~h}$ after starting the modality; those on Vapotherm had more normal examinations of the nasal mucosa than did those on unhumidified high flow. Campbell et al. [13] used digital photography to score the nasal mucosa on days 1, 7 and 30 following extubation but did not observe any significant nasal damage in either group. Iranpour et al. [33] used a nasal trauma scoring system and reported that infants treated with HFNC had significantly less trauma than those on NCPAP.

Although the above results are reassuring, the limitations of these studies mean that the safety of HFNC in the preterm population has yet to be adequately demonstrated. Until larger randomised studies are complete, the safety of HFNC will not have been established.

\section{Recommendations}

Surveys show that HFNC is widely used to treat preterm infants, and there is growing evidence of its feasibility as an alternative to other forms of non-invasive ventilation. However, there remains uncertainty about the efficacy and safety of HFNC in this population, and there are no long-term outcome data.
If HFNC is to be used, we recommend only heated, humidified HFNC systems with flow rates $\geq 2$ litres/min, up to the maximum flow rate recommended by the manufacturer. The use of improperly humidified gases may lead to drying of the airway mucosa and increase the risk of infection, as well as thick and dry secretions. Also, in our experience, the use of flow rates lower than 2 litres/ min tends to increase the amount of condensation in the tubing. Prongs should be chosen so as not to completely occlude the nares. When setting the flow rate, the infant's weight must be considered as pressure generation increases with decreasing infant size. A starting flow rate of 4-6 litres/min in newly born preterm infants would seem like a reasonable balance between efficacy and safety based on the available evidence and current clinical practices, with infants $<1 \mathrm{~kg}$ starting at the lower end of that range.

Research should concentrate on the pragmatic questions of 'does it work?' and 'is it safe?' compared to the current gold standard non-invasive support, NCPAP. There is still the need to define effective and safe minimum and maximum flow rates for the preterm population. Several RCTs that are studying HFNC as post-extubation support and as a primary therapy for RDS are under way. Until the results of these trials are known, widespread use of HFNC to treat preterm infants cannot be recommended.

\section{Disclosure Statement}

None of the authors has a conflict of interest to declare.

Appendix (see next page) 


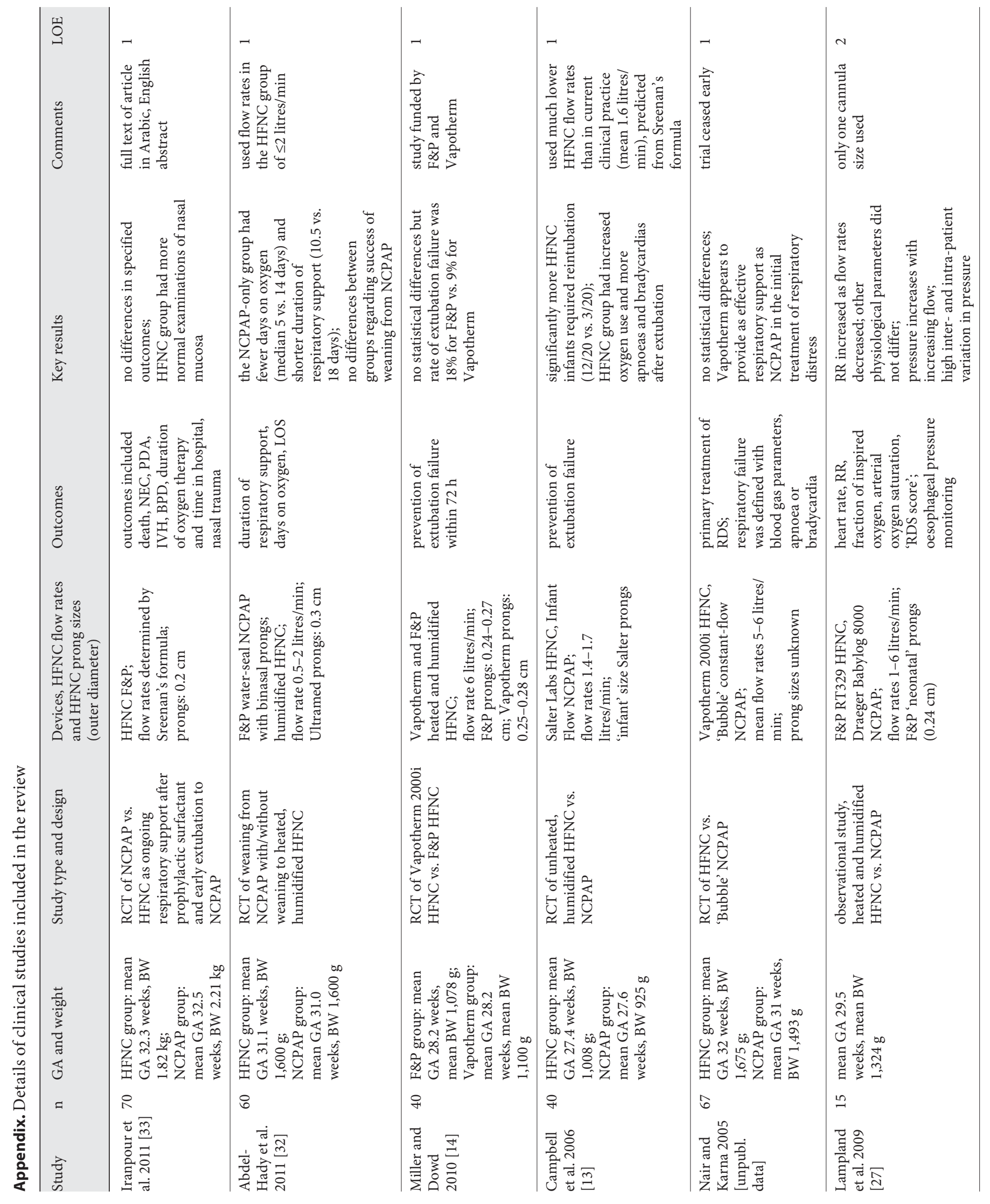




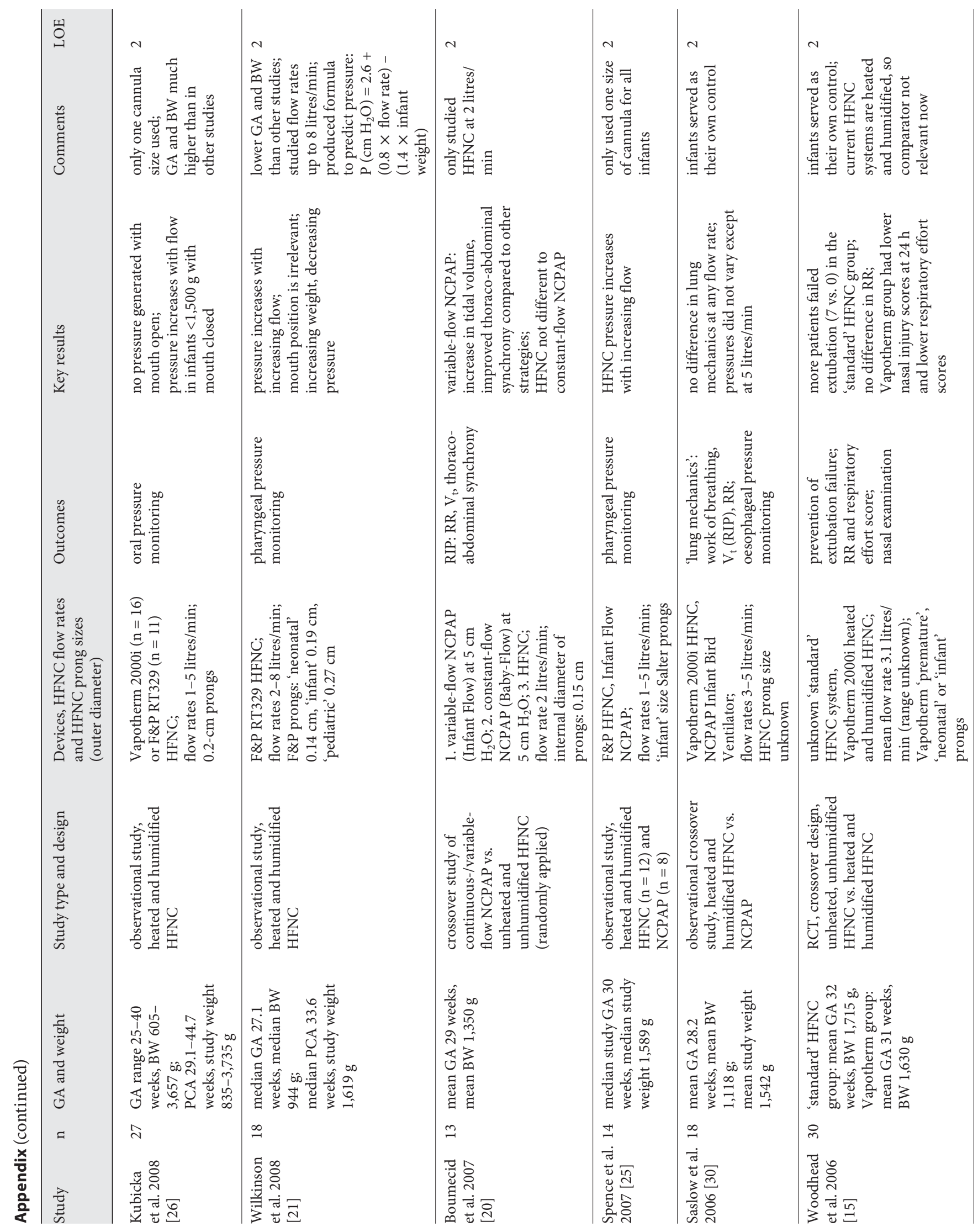




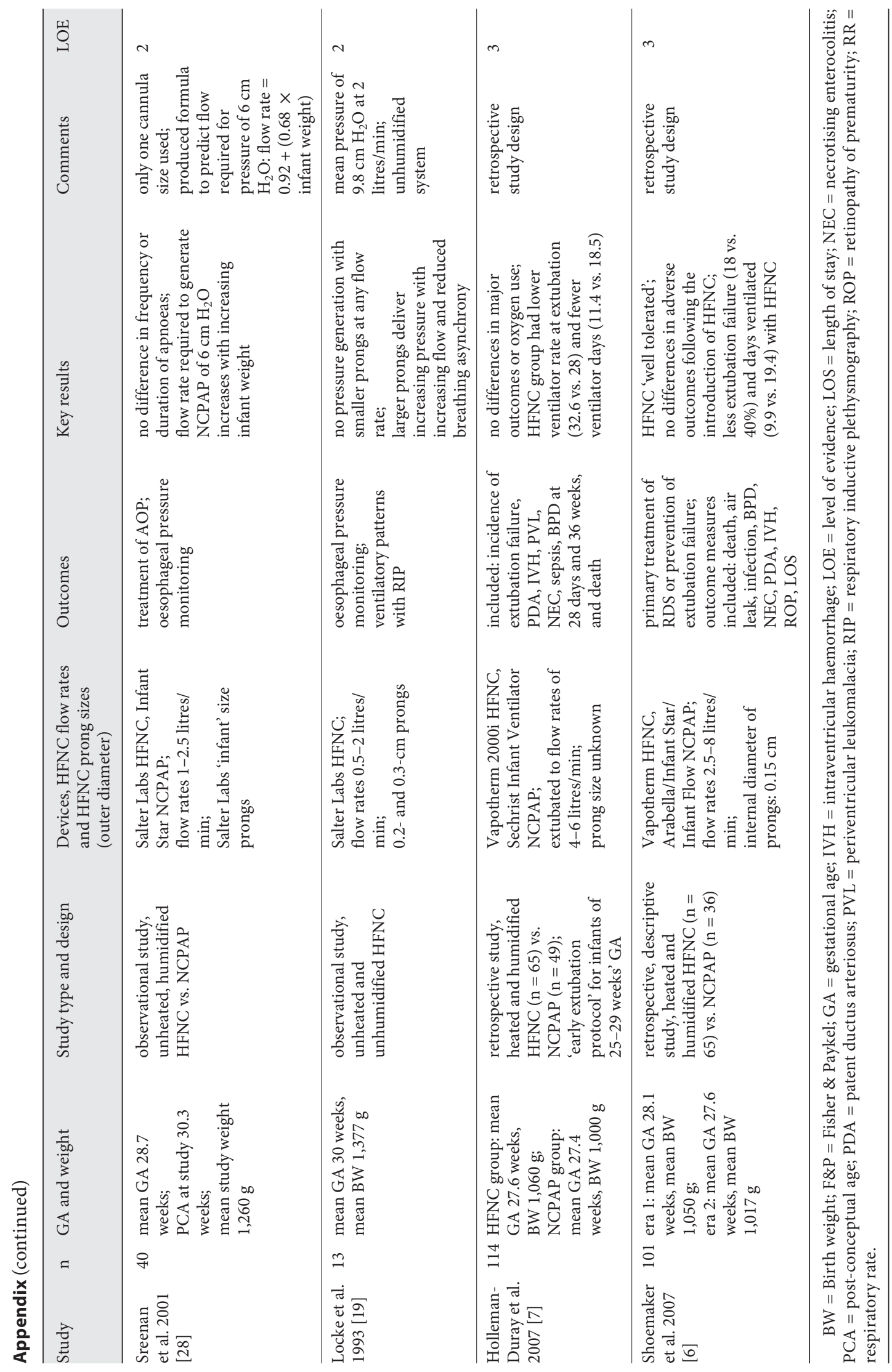




\section{References}

1 Wilkinson D, Andersen C, O'Donnell CP, et al: High flow nasal cannula for respiratory support in preterm infants. Cochrane Database Syst Rev 2011;5:CD006405.

-2 Spentzas T, Minarik M, Patters AB, et al: Children with respiratory distress treated with high-flow nasal cannula. J Intensive Care Med 2009;24:323-328.

-3 McKiernan C, Chua LC, Visintainer PF, et al: High flow nasal cannulae therapy in infants with bronchiolitis. J Pediatr 2010;156:634638.

4 Schibler A, Pham TM, Dunster KR, et al: Reduced intubation rates for infants after introduction of high-flow nasal prong oxygen delivery. Intensive Care Med 2011;37:847852.

5 Hochwald O, Osiovich $\mathrm{H}$ : The use of high flow nasal cannulae in neonatal intensive care units: is clinical practice consistent with the evidence? J Neonatal Perinatal Med 2010 3:187-191

-6 Shoemaker MT, Pierce MR, Yoder BA, et al: High flow nasal cannula versus nasal CPAP for neonatal respiratory disease: a retrospective study. J Perinatol 2007;27:85-91.

7 Holleman-Duray D, Kaupie D, Weiss MG Heated humidified high-flow nasal cannula: use and a neonatal early extubation protocol. J Perinatol 2007;27:776-781.

8 Nath P, Ponnusamy V, Willis K, et al: Current practices of high and low flow oxygen therapy and humidification in UK neonatal units. Pediatr Int 2010;52:893-894.

$\checkmark 9$ Hough JL, Shearman AD, Jardine LA, et al: Humidified high flow nasal cannulae: current practice in Australasian nurseries, a survey. J Paediatr Child Health 2012;48:106113.

10 Manley BJ, Owen L, Doyle LW, et al: Highflow nasal cannulae and nasal continuous positive airway pressure use in non-tertiary special care nurseries in Australia and New Zealand. J Paediatr Child Health 2012;48: 16-21.

11 Waugh JB, Granger WM: An evaluation of 2 new devices for nasal high-flow gas therapy. Respir Care 2004;49:902-906.

12 Chang GY, Cox CA, Shaffer TH: Nasal cannula, CPAP, and high-flow nasal cannula: effect of flow on temperature, humidity, pressure, and resistance. Biomed Instrum Technol 2011;45:69-74.
13 Campbell DM, Shah PS, Shah V, et al: Nasal continuous positive airway pressure from high flow cannula versus Infant Flow for Preterm infants. J Perinatol 2006;26:546549.

14 Miller SM, Dowd SA: High-flow nasal cannula and extubation success in the premature infant: a comparison of two modalities. J Perinatol 2010;30:805-808.

15 Woodhead DD, Lambert DK, Clark JM, et al: Comparing two methods of delivering highflow gas therapy by nasal cannula following endotracheal extubation: a prospective, randomized, masked, crossover trial. J Perinatol 2006;26:481-485.

16 Frizzola M, Miller TL, Rodriguez ME, et al: High-flow nasal cannula: impact on oxygenation and ventilation in an acute lung injury model. Pediatr Pulmonol 2011;46:67-74.

17 Hasan RA, Habib RH: Effects of flow rate and airleak at the nares and mouth opening on positive distending pressure delivery using commercially available high-flow nasal cannula systems: a lung model study. Pediatr Crit Care Med 2011;12:e29-e33.

18 Volsko TA, Fedor K, Amadei J, et al: High flow through a nasal cannula and CPAP effect in a simulated infant model. Respir Care 2011;56:1893-1900.

19 Locke RG, Wolfson MR, Shaffer TH, et al: Inadvertent administration of positive enddistending pressure during nasal cannula flow. Pediatrics 1993;91:135-138.

20 Boumecid H, Rakza T, Abazine A, et al: In fluence of three nasal continuous positive airway pressure devices on breathing pattern in preterm infants. Arch Dis Child Fetal Neonatal Ed 2007;92:F298-F300.

21 Wilkinson DJ, Andersen CC, Smith K, et al: Pharyngeal pressure with high-flow nasal cannulae in premature infants. J Perinatol 2008;28:42-47.

22 Hazinski MF, Nolan JP, Billi JE, et al: Part 1: Executive summary: 2010 International Consensus on Cardiopulmonary Resuscitation and Emergency Cardiovascular Care Science With Treatment Recommendations. Circulation 2010;122:S250-S275.

23 Finer NN: Nasal cannula use in the preterm infant: oxygen or pressure? Pediatrics 2005; 116:1216-1217.

24 Finer NN, Mannino FL: High-flow nasal cannula: a kinder, gentler CPAP? J Pediatr 2009;154:160-162.
25 Spence KL, Murphy D, Kilian C, et al: Highflow nasal cannula as a device to provide continuous positive airway pressure in infants. J Perinatol 2007;27:772-775.

-26 Kubicka ZJ, Limauro J, Darnall RA: Heated humidified high-flow nasal cannula therapy: yet another way to deliver continuous positive airway pressure? Pediatrics 2008. 121:82-88.

27 Lampland AL, Plumm B, Meyers PA, et al: Observational study of humidified highflow nasal cannula compared with nasal continuous positive airway pressure. J Pediatr 2009;154:177-182.

-28 Sreenan C, Lemke RP, Hudson-Mason A, et al: High-flow nasal cannulae in the management of apnea of prematurity: a comparison with conventional nasal continuous positive airway pressure. Pediatrics 2001;107:1081-1083.

29 Fischer HS, Roehr CC, Proquitte H, et al: Is volume and leak monitoring feasible during nasopharyngeal continuous positive airway pressure in neonates? Intensive Care Med 2009;35:1934-1941.

30 Saslow JG, Aghai ZH, Nakhla TA, et al: Work of breathing using high-flow nasal cannula in preterm infants. J Perinatol 2006;26:476480.

31 Davis PG, Henderson-Smart DJ: Nasal continuous positive airways pressure immediately after extubation for preventing morbidity in preterm infants. Cochrane Database Syst Rev 2003;CD000143.

- 32 Abdel-Hady H, Shouman B, Aly H: Early weaning from CPAP to high flow nasal cannula in preterm infants is associated with prolonged oxygen requirement: a randomized controlled trial. Early Hum Dev 2011;87: 205-208.

33 Iranpour R, Sadeghnia A, Hesaraki M: Highflow nasal cannula versus nasal continuous positive airway pressure in the management of respiratory distress syndrome. J Isfahan Med School 2011;29:761-771.

- 34 Jhung MA, Sunenshine RH, Noble-Wang J, et al: A national outbreak of Ralstonia mannitolilytica associated with use of a contaminated oxygen-delivery device among pediatric patients. Pediatrics 2007;119:1061-1068.

35 Jasin LR, Kern S, Thompson S, et al: Subcutaneous scalp emphysema, pneumo-orbitis and pneumocephalus in a neonate on high humidity high flow nasal cannula. J Perinatol 2008;28:779-781 